$\frac{1519.9}{10} \quad$ Dr.1816-3

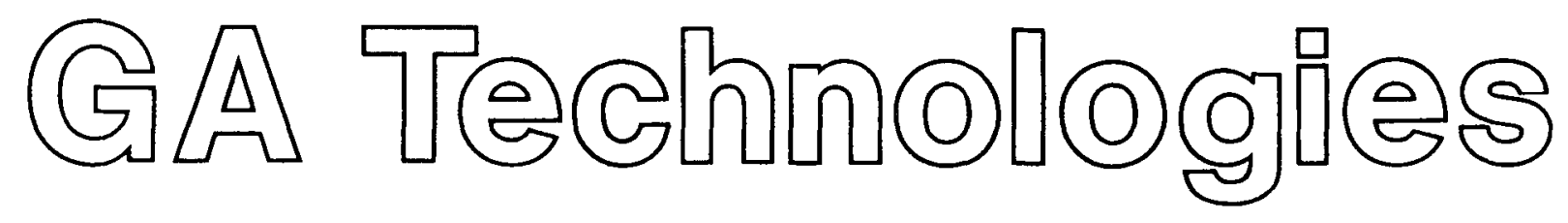

GA-A17146

UC-77

A NEW MATHEMATICAL METHOD FOR THE SOLUTION OF GAS-GAS EQUILIBRIA WITH SPECIAL APPLICATION TO

HTGR PRIMARY-COOLANT ENVIRONMENTS

by
Karl Bongartz

Prepared under

Contract DE-AT03-76ET35301

for the San Francisco Operations Office

Department of Energy

MADUin

JULY 1983 
This report was prepared as an account of work sponsored by an agency of the United States Government. Neither the United States Government nor any agency thereof, nor any of their employees, makes any warranty, express or implied, or assumes any legal liability or responsibility for the accuracy, completeness, or usefulness of any information, apparatus, product, or process disclosed, or represents that its use would not infringe privately owned rights. Reference herein to any specific commercial product, process, or service by trade name, trademark, manufacturer, or other-

wise, does not necessarily constitute or imply its endorsement, recommendation, or favoring by the United States Government or any agency thereof. The views and opinions of authors expressed herein do not necessarily state or reflect those of the United States Government or any agency thereof.

Printed in the United States of America Available from

National Technical Information Service

U.S. Department of Commerce 5285 Port Royal Road Springfield, Virginia 22161

Price Code: Printed Copy A03; Microfiche A01

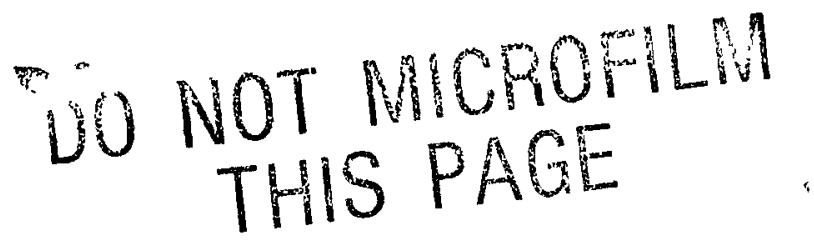




\section{DISCLAIMER}

This report was prepared as an account of work sponsored by an agency of the United States Government. Neither the United States Government nor any agency Thereof, nor any of their employees, makes any warranty, express or implied, or assumes any legal liability or responsibility for the accuracy, completeness, or usefulness of any information, apparatus, product, or process disclosed, or represents that its use would not infringe privately owned rights. Reference herein to any specific commercial product, process, or service by trade name, trademark, manufacturer, or otherwise does not necessarily constitute or imply its endorsement, recommendation, or favoring by the United States Government or any agency thereof. The views and opinions of authors expressed herein do not necessarily state or reflect those of the United States Government or any agency thereof. 


\section{DISCLAIMER}

Portions of this document may be illegible in electronic image products. Images are produced from the best available original document. 


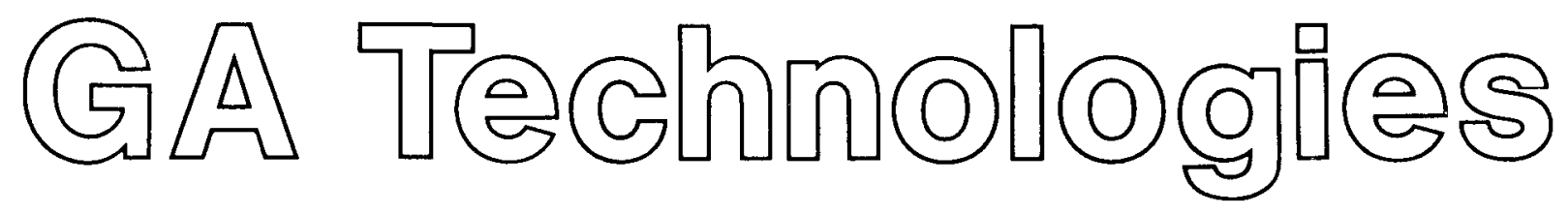

GA-A17146

UC-77

\title{
A NEW MATHEMATICAL METHOD FOR THE SOLUTION OF GAS-GAS EQUILIBRIA WITH SPECIAL APPLICATION TO HTGR PRIMARY-COOLANT ENVIRONMENTS
}

\author{
by \\ Karl Bongartz*
}

Prepared under

Contract DE-AT03-76ET35301

for the San Francisco Operations Office

Department of Energy

"Visiting Scientist, Kernforschungsanlage (Nuclear Research Center), Jitlich, West Germany.

GA PROJECT 7400 


\section{DISCLAIMER}

This report was prepared as an account of work sponsored by an agency of the United States Government. Neither the United States Government nor any agency thereof, nor any of their employees, makes any warranty, express or implied, or assumes any legal liability or responsibility for the accuracy, completeness, or usefulness of any information, apparatus, product, or process disclosed, or represents that its use would not infringe privately owned rights. Reference herein to any specific commercial product, process, or service by trade name, trademark, manufacturer, or otherwise does not necessarily constitute or imply its endorsement, recommendation, or favoring by the United States Government or any agency thereof. The views and opinions of authors expressed herein do not necessarily state or reflect those of the United States Government or any agency thereof. 
A new mathematical method and corresponding computer program have been developed that provide a general method for the numerical solution of an equilibrium problem involving the chemical interactions of gaseous species. The method and computer code were developed to calculate the equilibrium concentrations of impurity gases, such as $\mathrm{CO}, \mathrm{CO}_{2}, \mathrm{H}_{2}, \mathrm{H}_{2} \mathrm{O}, \mathrm{CH}_{4}$, and $\mathrm{O}_{2}$, which may be approached as the result of gaseous chemical reactions occurring within the hot primary coolant helium of a high-temperature gas-cooled reactor (HTGR). The method, however, can be applied to any gas mixture.

The technique developed is based on the solution of several independent equilibrium equations, each corresponding to a chemical equation relating the interaction of gaseous species, and associated with an equilibrium constant or product, and several equations associated with conservation of mass. The equilibrium equations are linearized by means of a Taylor expansion. The resulting system of linear equations is then solved by iteration. An initial guess for the individual impurity concentrations has to be made in order to start the iteration. This implies one fundamental problem: the guess has to be chosen appropriately so that it is already in the range of the desired solution in order to achieve convergence of the iterations. In order to avoid this difficulty, a new method was developed, the main feature of which is the construction of an artificial solution that serves as an initial guess to start the iterations. This solution is constructed by inserting the initial concentrations into the equilibrium product equations (equilibrium constants, $\mathrm{K}_{\mathrm{P}}$ ). This yields fictitious values for the equilibrium constants, $K_{P}$. Together with these $K_{P}$ 's, the initial concentrations are a solution to the mathematical problem even though not yet at the $\mathrm{K}_{\mathrm{P}}$ values given. The $\mathrm{K}_{\mathrm{P}}$ 's are then varied in small increments between the fictitious values for which the solution already exists and those given for which the solution is desired. After each increment, a new set of concentrations is calculated by iteration using the previous solution as a guess. 
The new model and computer code are described in detail. To test the applicability and correctness of the method, it was applied to recalculate the equilibrium gas compositions of various high-temperature, mixed gas, metal corrosion test environments that have been previously calculated by other authors with different methods. The results were in exact agreement. Especlally significant features, such as the strong influence of the initial water and oxygen content on the carbon activity and oxygen potential at equilibrium, become clear.

It should be emphasized that in practical applications such as the helium primary coolant of an HTGR, where coolant flow rates, by design, are very high, and in controlled-impurity helium corrosion experiments simulating an HTGR environment, in which hellum flow rates are deliberately maintained at high levels to minimize changes in gas composition via depletion effects, gas-gas interactions, etc., equilibrium conditions will not preval1. The numerical solution to any particular gas equilibrium problem, therefore, represents a condition which may, more than likely, only be approached in actual operating gas environments such as those identified above. 
CONTENTS

ABSTRACT . . . . . . . . . . . . . . . . . . . 1 . 1 . .

1. INTRODUCTION . . . . . . . . . . . . . . . . . . 1-1

2. THE MATHEMATICAL PROBLEM . . . . . . . . . . . . . . . 2-1

2.1. The Equilibrium Reactions of the Gases . . . . . . . . 2-1

2.2. The Conservation of the Gram Atoms of Oxygen $\overline{0}$, Hydrogen

$\overline{\mathrm{H}}$, and Carbon $\overline{\mathrm{C}}$............... 2-2

3. THE MATHEMATICAL APPROACH ................. 3-1

3.1. The Setup of the Equations for the Mathematical

Treatment ............... 3-1

3.2. The Linearization of the Nonlinear Equations of the System

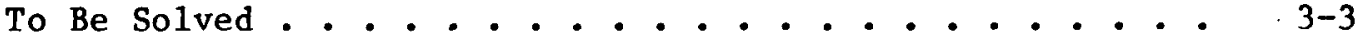

4. THE SYSTEM OF LINEARIZED EQUATIONS AND THEIR SOLUTIONS . . . • 4-1

4.1. Setup of the System of Linear Equations . . . . . . . . 4-1

4.2. The Iterative Method for Solving the Equations . . . . 4-3

5. THE NEW METHOD AVOIDING THE INITIAL GUESS FOR THE ITERATION - • 5-1

5.1. Solution Without Considering the Carbon Potential . . . 5-1

5.2. Consideration of the Carbon Potential ac of the Gas Mixture, Calculation of a Possible Carbon Plateout, and the Resulting New Gas Equilibrium if ac $>1$. . . . . 5-2

6. THE COMPUTER PROGRAM BASED UPON THE MODEL . . . . . . . . . 6-1

6.1. The Subroutine CONCEN . . . . . . . . . . . . 6-1

6.2. The Subroutines LINEQ and DETERM ............ 6-3

6.3. The MAIN Routine ................ 6-3

6.3.1. The Input of the Program ......... 6-4

6.3.2. Construction of the Fictitious Solution Necessary to Start the Iterative Solution Procedure and Rearrangement of the Initial Concentrations if Initial $\mathrm{O}_{2}$ Concentration is Greater than 0 . . 6-5

6.3.3. The Variation of $\mathrm{K}_{\mathrm{P}_{1}}+\mathrm{K}_{\mathrm{P}_{3}}$ by Increments . . . . 6-6

6.3.4. Equilibrium Calculation When Carbon Plateout
Takes Place ............... 6-7 
7. CALCULATIONS PERFORMED WITH THE NEW MODEL . . . . . . . . 7-1

7.1. Calculation of the Equilibrium of Two Test Gases . . . . 7-1

7.2. Calculation of the Influence of the Initial Oxygen and Water Content on the Carbon and Oxygen Potentials of the JAERI-A Test Gas at $800^{\circ}$ and $1000^{\circ} \mathrm{C}$. . . . . . . 7-3

8. REFERENCES . . . . . . . . . . . . . . . . 8-1

9. ACKNOWLEDGMENTS . . . . . . . . . . . . . . . 9-1

\section{FIGURES}

1. Effect of oxygen addition on the carbon activity and oxygen potential in the JAERI-A gas at $800^{\circ}$ and $1000^{\circ} \mathrm{C}$. . . . . . 7-5

2. Effect of water variation on the carbon activity and oxygen potential in the JAERI-A gas at $800^{\circ}$ and $1000^{\circ} \mathrm{C} . . . . . .6$

TABLES

1. Two impure gases for material tests . . . . . . . . 7-2

2. Calculated equilibrium gas concentrations . . . . . . . . 7-4 


\section{INTRODUCTION}

The high-temperature gas-cooled reactor (HTGR) uses graphite as a moderator and helium as a primary coolant at temperatures approaching $\sim 800^{\circ} \mathrm{C}$ $\left(1472^{\circ} \mathrm{F}\right)$. Helium, which is itself chemically inert, is contaminated during its circulation through the reactor with small amounts of $\mathrm{H}_{2}, \mathrm{H}_{2} \mathrm{O}, \mathrm{CO}, \mathrm{CO}_{2}$, $\mathrm{CH}_{4}$, and $\mathrm{O}_{2}$. These impurities arise from a variety of sources, including outgassing of internal components, inleakage of impurities (e.g.., $\left.\mathrm{H}_{2} \mathrm{O}\right)$, and subsequent reaction with the graphite core, etc.

The internal structural materials of the reactor are exposed to this impure helium at elevated temperatures, producing corrosion effects that can degrade the long-term structural integrity or properties of the materials. It has been, therefore, the scope of many investigations to quantitatively determine these effects in order that such degradation in properties can be factored into component design. Tests for this purpose have involved the exposure of alloys at elevated temperatures in helium containing impurities at concentrations simulating the primary coolant environment of an operating HTGR.

Previous studies have shown that oxidation and carburization can occur, depending upon alloy chemistry, helium chemistry, and exposure temperature. Carburization has been identified as the key concern for metallic structural materials. This phenomenon, although produced via interaction between the metal surfaces and the carbon-bearing impurities (e.g., $\mathrm{CO}, \mathrm{CH}_{4}$ ) in the hellum, is strongly affected by oxygen-bearing species such as $\mathrm{CO}_{2}$ and $\mathrm{H}_{2} \mathrm{O}$. Thus, both carbon and oxygen potentials in the gas are important parameters with regard to materfal behavior. In general, experimental test gases for studies of the helium compatibility of candidate materials are prepared at room temperature. As chemical reactions, which are temperature dependent,

can take place at the test temperature, the gas composition may change. In 
the limit of chemical reactivity, the gas composition may approach the state of thermodynamic equilibrium, i.e., constant carbon and oxygen potential. It is in this latter context that the following method for calculating the equilibrium concentrations of gaseous impurities in a helium environment was derived. 


\section{THE MATHEMATICAL PROBLEM}

\subsection{THE EQUILIBRIUM REACTIONS OF THE GASES}

The gas mixture considered herein is helium containing small and Initially specified amounts of $\mathrm{H}_{2}, \mathrm{H}_{2} \mathrm{O}, \mathrm{CO}, \mathrm{CO}_{2}, \mathrm{CH}_{4}$, and $\mathrm{O}_{2}$, consistent with that contained in an HTGR primary coolant. We will consider the interaction of the various gaseous impurities in this gas mixture using the principles of thermodynamic equllibrium first used by Darken and Gurry (Ref. 1) in their now classic treatment of a similar mixture of gases.

For the system of gases to be treated, several equilibria and corresponding equilibrium constants, $K_{P}$, have been chosen, as follows:

$$
\begin{array}{ll}
\mathrm{CH}_{4}+\mathrm{H}_{2} \mathrm{O}=\mathrm{CO}+3 \mathrm{H}_{2} & \mathrm{~K}_{\mathrm{P}_{1}}=\frac{\mathrm{P}_{\mathrm{CO}} \cdot \mathrm{P}_{\mathrm{H}_{2}}^{3}}{\mathrm{P}_{\mathrm{CH}_{4}} \cdot \mathrm{P}_{\mathrm{H}_{2} \mathrm{O}}} \\
\mathrm{CH}_{4}+\mathrm{CO}_{2}=2 \mathrm{CO}+2 \mathrm{H}_{2} & \mathrm{~K}_{\mathrm{P}_{2}}=\frac{\mathrm{P}_{\mathrm{CO}}^{2} \cdot \mathrm{P}_{\mathrm{H}_{2}}^{2}}{\mathrm{P}_{\mathrm{CH}_{4}} \cdot \mathrm{P}_{\mathrm{CO}_{2}}} \\
\mathrm{H}_{2}+1 / 2 \mathrm{O}_{2}=\mathrm{H}_{2} \mathrm{O} & \mathrm{K}_{\mathrm{P}_{3}}=\frac{\mathrm{P}_{\mathrm{H}_{2} \mathrm{O}}}{\mathrm{P}_{\mathrm{H}_{2}} \cdot \mathrm{P}_{\mathrm{O}_{2}}{ }^{1 / 2}} \\
\mathrm{CH}_{4}=\mathrm{C}+2 \mathrm{H}_{2} & \mathrm{~K}_{\mathrm{P}_{4}}=\frac{{ }_{C} \cdot \mathrm{P}_{\mathrm{H}_{2}}^{2}}{\mathrm{P}_{\mathrm{CH}_{4}}}
\end{array}
$$

$\mathrm{K}_{\mathrm{P}_{1}}, \mathrm{~K}_{\mathrm{P}_{2}}, \mathrm{~K}_{\mathrm{P}_{3}}$, and $\mathrm{K}_{\mathrm{P}_{4}}$ are the equilibrium constants, and $\mathrm{P}_{\mathrm{H}_{2}} \mathrm{O}, \mathrm{P}_{\mathrm{H}_{2}}, \mathrm{P}_{\mathrm{CH}_{4}}$, $\mathrm{P}_{\mathrm{CO}}, \mathrm{P}_{\mathrm{CO}_{2}}$, and $\mathrm{P}_{2}$ are the partial pressures of water vapor, hydrogen, methane, carbon monoxide, carbon dioxide and oxygen, respectively. The 
activity of carbon is ac. There are other reactions that occur, but those quoted above suffice to define the problem.

\subsection{THE CONSERVATION OF THE GRAM ATOMS OF OXYGEN $\overline{0}$, HYDROGEN $\overline{\mathrm{H}}$, AND CARBON $\bar{C}$}

The number of gram atoms of each element in the mixture, oxygen $\overline{0}$, hydrogen $\overline{\mathrm{H}}$, and carbon $\overline{\mathrm{C}}$, is independent of the distribution of concentrations for the individual impurity species. If $n_{1}^{0}$ denotes the initial molar concentration and $n_{1}$ the equilibrium concentration at the temperature in question, we have, for mass conservation,

$$
\begin{aligned}
& \overline{0}=\stackrel{\circ}{\mathrm{n} O}+2 \stackrel{\circ}{\mathrm{CO}}_{2}+\stackrel{\circ}{\mathrm{n}_{2} \mathrm{O}},+2{\stackrel{\circ}{\mathrm{n}_{2}}}^{\circ} \\
& =n_{\mathrm{CO}}+2 n_{\mathrm{CO}_{2}}+n_{\mathrm{H}_{2} \mathrm{O}}+2 n_{\mathrm{O}_{2}} \\
& \overline{\mathrm{H}}=2 \mathrm{n}_{\mathrm{H}_{2}}^{\circ}+2 \mathrm{n}_{\mathrm{H}_{2} \mathrm{O}}^{\circ}+4 \mathrm{n}_{\mathrm{CH}_{4}}^{\circ} \\
& =2 \mathrm{n}_{2}+2 \mathrm{n}_{\mathrm{H}_{2} \mathrm{O}}+4 \mathrm{n}_{\mathrm{CH}_{4}} \\
& \overline{\mathrm{C}}=\stackrel{\circ}{\mathrm{n}_{\mathrm{CH}}}+\stackrel{\circ}{\mathrm{n}_{\mathrm{CO}}}+\stackrel{\circ}{\mathrm{n}_{\mathrm{CO}}} \\
& =\mathrm{n}_{\mathrm{CH}_{4}}+\mathrm{n}_{\mathrm{CO}}+\mathrm{n}_{\mathrm{CO}_{2}}
\end{aligned}
$$

The molar concentrations $n_{1}$ and partial pressures $P_{1}$ are given by the relation

$$
P_{1}=\frac{n_{1}}{n_{T}} P_{T}
$$


where $P_{\mathrm{T}}$ is the total pressure and $\mathrm{n}_{\mathrm{T}}$, the total molar concentration, is given by

$$
\mathrm{n}_{\mathrm{T}}=\mathrm{n}_{\mathrm{H}_{2} \mathrm{O}}+\mathrm{n}_{\mathrm{H}_{2}}+\mathrm{n}_{\mathrm{O}_{2}}+\mathrm{n}_{\mathrm{CO}}+\mathrm{n}_{\mathrm{CO}_{2}}+\mathrm{n}_{\mathrm{CH}_{4}}+\mathrm{n}_{\mathrm{CG}}
$$

Here, $n_{C G}$ is the concentration of the inert carrier gas, which in the following cases is helium. It could be the sum of different inert gases as we11. 


\section{THE MATHEMATICAL APPROACH}

3.1. THE SETUP OF THE EQUATIONS FOR THE MATHEMATICAL TREATMENT

Equations 2-1 through 2-7 are used for the determination of the equilibrium concentrations of the gases. In order to simplify the mathematical treatment, the nomenclature for the concentrations is changed as follows:

$$
\begin{aligned}
& \mathrm{x}_{1}=\mathrm{n}_{\mathrm{H}_{2}} ; \quad \mathrm{x}_{2}=\mathrm{n}_{\mathrm{CO}} ; \quad \mathrm{x}_{3}=\mathrm{n}_{\mathrm{CH}_{4}} ; \\
& \mathrm{x}_{4}=\mathrm{n}_{\mathrm{H}_{2} \mathrm{O}} ; \quad \mathrm{x}_{5}=\mathrm{n}_{\mathrm{CO}_{2}} ; \\
& \mathrm{x}_{7}=\mathrm{n}_{\mathrm{CG}} .
\end{aligned}
$$

Using Eq. 2-8, the partial pressures $P_{1}$ in Eqs. 2-1 through 2-4 can be expressed in terms of the molar concentrations $n_{1}$ or $x_{1}$. Furthermore, in practical applications, $P_{T}=1$ atm; therefore, for $P_{T}=1$, we have

$$
\begin{aligned}
& \mathrm{K}_{\mathrm{P}_{1}}=\frac{\mathrm{x}_{1}^{3} \mathrm{x}_{2}}{\mathrm{x}_{3} \mathrm{x}_{4}} \frac{1}{\mathrm{x}_{\mathrm{T}}^{2}} \\
& \mathrm{~K}_{2}=\frac{\mathrm{x}_{1}^{2} \mathrm{x}_{2}^{2}}{\mathrm{x}_{3} \mathrm{x}_{5}} \frac{1}{\mathrm{x}_{\mathrm{T}}^{2}} \\
& \mathrm{~K}_{3}=\frac{\mathrm{x}_{4}}{\mathrm{x}_{1} \mathrm{x}_{6}{ }^{1 / 2}} \mathrm{x}_{\mathrm{T}}^{1 / 2}
\end{aligned}
$$




$$
\mathrm{K}_{\mathrm{P}_{4}}=\frac{{ }^{{ }_{C} \mathrm{x}_{1}^{2}}}{\mathrm{x}_{3}} \frac{1}{\mathrm{x}_{\mathrm{T}}}
$$

$\mathrm{K}_{\mathrm{P}_{1}}, \mathrm{~K}_{\mathrm{P}_{2}}, \mathrm{~K}_{\mathrm{P}_{3}}$, and $\mathrm{K}_{\mathrm{P}_{4}}$ are the equilibrium constants given for a certain temperature.

Equations 2-5 through 2-7 and 3-2 through 3-5 are the seven equations that determine $x_{1}+x_{6}$ (read $" x_{1}+x_{6} "$ as $\left." x_{1}, x_{2}, \ldots, x_{6} "\right)$ and $a_{C} \cdot a_{C}$ appears only in Eq. 3-5; therefore, this equation is left out at first and $\mathrm{x}_{1}+\mathrm{x}_{6}$ are solved using Eqs. 2-5 through 2-7 and 3-2 through 3-4, thus reducing the problem to solving six equations for the six unknowns $x_{1} \rightarrow x_{6}$. $a_{C}$ can then be calculated using Eq. 3-5. The system to be solved was further simplified by keeping in mind that the oxygen concentration $n_{0_{2}}=x_{6}$ is always small because $\mathrm{K}_{\mathrm{P}_{3}}$ has relatively high values. $\mathrm{x}_{6}$ appears in Eqs. 3-4 and 2-5 only. Therefore, Eq. 3-4 was left out of the system to be solved first and $x_{6}$ was regarded as a small correction term in Eq. 2-5. This reduces the system of equations to be solved to five, 1.e., Eqs. 2-5 through $2-7,3-2$, and 3-3, the unknowns being $x_{1} \rightarrow x_{5}$. The term $2 x_{6}$ in Eq. 2-5 is shifted to the left side of this equation. Since $x_{6}$ is considered a small correction term, we denote it as $x_{6}^{\prime}$. Equations 2-5 through 2-7 now take the form

$$
\begin{aligned}
\overrightarrow{0}-2 x_{6}^{\prime} & =x_{2}+x_{4}+2 x_{5} \\
& =x_{2}^{\circ}+x_{4}^{\circ}+2 x_{5}^{\circ} \\
\bar{H} & =2 x_{1}+4 x_{3}+2 x_{4} \\
& =2 x_{1}^{\circ}+4 x_{3}^{\circ}+2 x_{4}^{\circ} \\
\bar{C} & =x_{2}+x_{3}+x_{5} \\
& =x_{2}^{\circ}+x_{3}^{\circ}+x_{5}^{\circ}
\end{aligned}
$$


The system of Eqs. 3-2, 3-3, and 3-6 through 3-8 is solved by an iterative procedure that will be described later. To start the 1teration, $x_{6}^{\prime}$ has to be given the value zero. After the solution of the system $x_{1} \rightarrow x_{5}$ is calculated, $x_{6}$ can then be calculated using Eq. 3-4. Before the next iteration, $x_{6}^{\prime}$ is set equal $x_{6}$ and inserted into Eq. 3-6, etc.

\subsection{THE LINEARIZATION OF THE NONLINEAR EQUATIONS OF THE SYSTEM TO BE SOLVED}

The solution of the system of Eqs. 3-6 through 3-8,3-2, and 3-3 for the unknowns $x_{1}+x_{5}$ is the central problem of this task. Because Eqs. 3-2 and 3-3 are nonlinear in the $x_{1}$, the solution cannot be given straightforward analytically. In order to arrive at an analytical approach, Eqs. 3-2 and 3-3 were linearized using a Taylor expansion.

These two equations can be written in the form

$$
\begin{aligned}
& \mathrm{K}_{\mathrm{P}_{1}}=\mathrm{F}_{1} \text { with } \mathrm{F}_{1}=\frac{\mathrm{x}_{1}^{3} \mathrm{x}_{2}}{\mathrm{x}_{3} \mathrm{x}_{4}} \frac{1}{\mathrm{x}_{\mathrm{T}}^{2}} \\
& \mathrm{~K}_{\mathrm{P}_{2}}=\mathrm{F}_{2} \text { with } \mathrm{F}_{2}=\frac{\mathrm{x}_{1}^{2} \mathrm{x}_{2}^{2}}{\mathrm{x}_{3} \mathrm{x}_{5}} \frac{1}{\mathrm{x}_{\mathrm{T}}^{2}}
\end{aligned}
$$

Expanding $F_{1}$ in a Taylor series and neglecting nonlinear terms in $x_{i}$ yields

$$
\begin{gathered}
F_{1}\left(x_{1}, \ldots, x_{5}\right) \approx F_{1}^{\prime}+\frac{\partial F_{1}^{\prime}}{\partial x_{1}}\left(x_{1}-x_{1}^{\prime}\right)+\frac{\partial F_{1}^{\prime}}{\partial x_{2}}\left(x_{2}-x_{2}^{\prime}\right) \\
+\ldots+\frac{\partial F_{1}^{\prime}}{\partial x_{5}}\left(x_{5}-x_{5}^{\prime}\right)
\end{gathered}
$$


There $x_{n}^{\prime}, \ldots, x_{5}^{\prime}$ are values that have to be near enough to $x_{1}, \ldots, x_{5}$ that the nonlinear terms in the expansion may be neglected. [Fi denotes $\left.F_{1}\left(x_{1}^{\prime}, \ldots, x_{5}^{\prime}\right).\right]$

For $F_{2}$ we have

$$
\begin{gathered}
F_{2}\left(x_{1}, \ldots, x_{5}\right) \approx F_{2}^{\prime}+\frac{\partial F_{2}^{\prime}}{\partial x_{1}}\left(x_{1}-x_{1}^{\prime}\right)+\frac{\partial F_{2}^{\prime}}{\partial x_{2}}\left(x_{2}-x_{2}^{\prime}\right) \\
+\ldots+\frac{\partial F_{2}^{\prime}}{\partial x_{5}}\left(x_{5}-x_{5}^{\prime}\right) .
\end{gathered}
$$

Using Eqs. 3-9 and 3-10, the derivative terms in Eqs. 3-11 and 3-12 can be written as

$$
\begin{aligned}
& \frac{\partial F_{1}^{\prime}}{\partial x_{1}^{\prime}}=\frac{3 F_{1}^{\prime}}{x_{1}^{\prime}}-\frac{2 F_{1}^{\prime}}{x_{T}^{\prime}} ; \quad \frac{\partial F_{1}^{\prime}}{\partial x_{2}^{\prime}}=\frac{F_{1}^{\prime}}{x_{2}^{\prime}}-\frac{2 F_{1}^{\prime}}{x_{T}^{\prime}} \quad ; \text { etc. } \\
& \frac{\partial F_{2}^{\prime}}{\partial x_{1}^{\prime}}=\frac{2 F_{2}^{\prime}}{x_{1}^{\prime}}-\frac{2 F_{2}^{\prime}}{x_{T}^{\prime}} ; \quad \frac{\partial F_{2}^{\prime}}{\partial x_{2}^{\prime}}=\frac{2 F_{2}^{\prime}}{x_{2}^{\prime}}-\frac{2 F_{2}^{\prime}}{x_{T}^{\prime}} \quad ; \text { etc. }
\end{aligned}
$$


4. THE SYSTEM OF LINEARIZED EQUATIONS AND THEIR SOLUTIONS

4.1. SETUP OF THE SYSTEM OF LINEAR EQUATIONS

Inserting Eq. 3-13 into 3-11 and Eq. 3-14 into 3-12 first, and then Eq. 3-11 into 3-9 and Eq. 3-12 into 3-10, we can rewrite the system of Eqs. 3-6 through 3-10 in a form where all equations are linear:

$$
\begin{aligned}
& B_{1}=\sum_{j=1}^{5} \alpha_{1 j} x_{j} . \\
& B_{2}=\sum_{j=1}^{5} \alpha_{2 j} x_{j} . \\
& B_{3}=\sum_{j=1}^{5} \alpha_{3 j} x_{j} . \\
& B_{4}=\sum_{j=1}^{5} \alpha_{4 j} x_{j} \\
& B_{5}=\sum_{j=1}^{5} \alpha_{5 j} x_{j}
\end{aligned} .
$$


These are the equations to be solved for $x_{1}+x_{5}$. The coefficients are derived from Eqs. 3-6 through 3-8 and according to section 3.2. The coefficlents of the system of Eqs. 4-1 through 4-5 are

$$
\begin{aligned}
& B_{1}=\bar{O}-2 x_{6}^{\prime} \quad ; \quad B_{2}=\overline{\mathrm{H}} \quad ; \quad B_{3}=\bar{C} \quad ; \\
& B_{4}=K_{P_{1}}+F_{1}^{\prime}\left(1-2 \frac{1}{x_{T}^{\prime}} \sum_{j=1}^{5} x_{j}^{\prime}\right) ; \\
& B_{5}=K_{P_{2}}+F_{2}^{\prime}\left(1-2 \frac{1}{x_{T}^{\prime}} \sum_{j=1}^{5} x_{j}^{\prime}\right) \\
& \alpha_{11}=0, \quad \alpha_{12}=1, \quad \alpha_{13}=0, \quad \alpha_{14}=1 \\
& \alpha_{15}=2, \quad \alpha_{21}=2, \alpha_{22}=0, \quad \alpha_{23}=4, \\
& \alpha_{24}=2, \quad \alpha_{25}=0, \quad \alpha_{31}=0, \quad \alpha_{32}=1, \\
& \alpha_{33}=1, \quad \alpha_{34}=0, \alpha_{35}=1, \\
& \alpha_{41}=\frac{3 F_{1}^{\prime}}{x_{1}^{\prime}}-\frac{2 F_{1}^{\prime}}{x_{T}^{\prime}}, \quad \alpha_{42}=\frac{F_{1}^{\prime}}{x_{2}^{\prime}}-\frac{2 F_{1}^{\prime}}{x_{T}^{\prime}}, \quad \alpha_{43}=-\frac{F_{1}^{\prime}}{x_{3}^{\prime}}-\frac{2 F_{1}^{\prime}}{x_{T}^{\prime}}, \\
& \alpha_{44}=-\frac{F_{1}^{\prime}}{x_{4}^{\prime}}-2 \frac{F_{1}^{\prime}}{x_{T}^{\prime}}, \quad \alpha_{45}=-2 \frac{F_{1}^{\prime}}{x_{T}^{\prime}}, \quad \alpha_{51}=2 \frac{F_{2}^{\prime}}{x_{1}^{\prime}}-2 \frac{F_{2}^{\prime}}{x_{T}^{\prime}}, \\
& \alpha_{52}=2 \frac{F_{2}^{\prime}}{x_{2}^{\prime}}-2 \frac{F_{2}^{\prime}}{x_{T}^{\prime}}, \quad \alpha_{53}=-\frac{F_{2}^{\prime}}{x_{3}^{\prime}}-2 \frac{F_{2}^{\prime}}{x_{T}^{\prime}}, \quad \alpha_{54}=-2 \frac{F_{2}^{\prime}}{x_{T}^{\prime}}, \\
& \alpha_{55}=-\frac{F_{2}^{\prime}}{x_{5}^{\prime}}-2 \frac{F_{2}^{\prime}}{x_{T}^{\prime}} .
\end{aligned}
$$




\subsection{THE ITERATIVE METHOD FOR SOLVING THE EQUATIONS}

The coefficients in the linear system of equations depend on $x_{1}^{\prime}+x_{5}^{\prime}$. According to their definition (see Eqs. 3-11 and 3-12), they have to be near the solution of the problem, which is $x_{1} \rightarrow x_{5}$. This leads to an iterative procedure of solution. An assumption has to be made as to where the solution might be, leading to a certain guess for the initial set of values $x_{1}^{\prime}-x_{5}^{\prime}\left(x_{6}^{\prime}=0\right)$ to be inserted into the coefficients $B_{1}, B_{i}, \alpha_{i j}, 1=4,5$, $j=1,5$, in Eqs. 4-6 and 4-7. With these coefficients, the system Eqs. 4-1 through 4-5 can be solved giving a solution $x_{1} \rightarrow x_{5} \cdot x_{6}$ is calculated from this solution using Eq. 3-4. Then this solution $x_{1} \rightarrow x_{6}$ is used as a guess $\left(x_{1}^{\prime} \rightarrow x_{6}^{\prime}\right)$ for the next iteration, etc., until $x_{1} \rightarrow x_{6}$ converge, i.e., the final solution is found.

When the final solution is found, the carbon activity ${ }^{a} \mathrm{C}$ is calculated using Eq. 3-5.

The problem with the procedure described above is that a suitable guess $x_{1}^{\prime} \rightarrow x_{5}^{\prime}$ must be made near enough to the physical solution of the problem that the iteration converges toward this solution $\mathrm{x}_{1} \rightarrow \mathrm{x}_{6}$. If the guess is not good enough, the iteration will most likely diverge or may possibly converge to one of the possible mathematical solutions, which is not a physical solution, i.e., a solution with one or more values $x_{1}$ which are less than zero.

In the following section, the new method is described that avoids this problem. Using this method, no initial guess has to be made for $x_{1}^{\prime}+x_{5}^{\prime}$; the only physical solution $\mathrm{x}_{1}+\mathrm{x}_{6}$ is calculated straightforwardly. 


\section{THE NEW METHOD AVOIDING THE INITIAL GUESS FOR THE ITERATION}

\subsection{SOLUTION WITHOUT CONSIDERING THE CARBON POTENTIAL}

The special feature of the new method is that a physical solution is constructed for the initial state of the concentration distribution of the gas constituents $n_{1}: x_{1}^{0} \rightarrow x_{5}^{\circ}$. If $\dot{n}_{0_{2}}^{\circ}=0,1 . e ., x_{6}^{\circ}=0$, then $\overline{0}, \bar{H}$ and $\bar{C}$ are calculated with Eqs. 2-5 through 2-7. Now fictitious values for $\mathrm{K}_{\mathrm{P}_{1}}$ and $\mathrm{K}_{\mathrm{P}_{2}}^{\circ}$ are calculated inserting $\mathrm{x}_{1}^{\circ} \rightarrow \mathrm{x}_{5}^{\circ}$ into Eqs. 3-2 and 3-3. A high fictitious value of $10^{30}$ has to be attributed to $\mathrm{K}_{\mathrm{P}_{3}}$. If either of the values $\mathrm{x}_{1}^{\circ}+\mathbf{x}_{5}^{\circ}$ is zero, a value low enough that it does not significantly contribute to the sums of Eqs. 2-5 through 2-7 has to be assumed for it, thus preventing the products of Eqs. 3-2 and 3-3 from becoming zero or infinite. Now the values $x_{1}^{0}+x_{0}^{0}$ may be regarded as a solution to the problem for the $K_{\mathrm{P}}$ 's being $\mathrm{K}_{\mathrm{P}_{1}}^{\circ}$ and $\mathrm{K}_{\mathrm{P}_{2}}^{\circ}$. In the case that $\mathrm{n}_{\mathrm{O}_{2}}^{\circ} \neq 0$ (i.e., $\mathrm{x}_{6}^{\circ} \neq 0$ ), a different solution has to be constructed since according to Eq. 2-5, the amount $2 \mathrm{n}_{\mathrm{O}_{2}}^{\circ} \equiv 2 \mathrm{x}_{6}^{\circ}$ has to be added to give $\overline{0}$. In the simplified system of Eqs. 3-6 through 3-8, $x_{6}^{\circ}$ no longer appears on the right side and $x_{6}^{\circ}$ has to be zero at the beginning. Therefore, $2 x_{6}^{0}$ is added to $x_{4}^{\circ}$ in Eq. 3-6 to give the proper amount of $\overline{0}$. In order to compensate for this in Eq. 3-7, i.e., leave $\overline{\mathrm{H}}$ unchanged, $2 x_{6}^{0}$ has to be subtracted from $x_{1}^{0}$. With these new $x_{1}^{0} \rightarrow x_{5}^{0}$, the $\mathrm{K}_{\mathrm{P}_{1}}$ and $\mathrm{K}_{\mathrm{P}_{2}}$ are calculated as described before, such that the new $\mathbf{x}_{1}^{0}+\mathbf{x}_{5}^{0}$ are a solution to the system of equations.

In order to arrive at the desired solution for the given $\mathrm{K}_{\mathrm{P}_{1}} \rightarrow \mathrm{K}_{\mathrm{P}_{3}}$, the three $\mathrm{K}_{P^{\prime}}$ 's are varied in small increments between $\mathrm{K}_{\mathrm{P}_{1}}^{\circ} \rightarrow \mathrm{K}_{\mathrm{P}_{3}}^{\circ}$ and the given values. After the first increment of the $\mathrm{K}_{\mathrm{P}}$ 's an iterative procedure can be started to solve the system of Eqs. 4-1 through 4-5 for the first guess $x_{1}^{\prime}+x_{6}^{\prime}$. The values $x_{1}^{\circ}+x_{5}^{\circ}$ and $x_{6}^{\prime}=0$; $1 . e .$, the values of the solution for the previous $\mathrm{K}_{\mathrm{p}}$ 's are used. The increment can be made small enough that the iteration converges toward a new solution $x_{1} \rightarrow x_{6}$ for the increased $K_{P}$ 's. The new solution can then be used as guess $x_{1}^{\prime}+x_{6}^{\prime}$ for the next 
increment, etc., until the $\mathrm{K}_{\mathrm{P}}$ 's have reached the values given and the desired solution is obtained.

5.2. CONSIDERATION OF THE CARBON POTENTIAL a OF THE GAS MIXTURE, CALCULATION OF A POSSIBLE CARBON PLATEOUT, AND THE RESULTING NEW GAS EQUILIBRIUM IF a $>1$

Using the solution for the $\mathrm{x}_{1} \rightarrow \mathrm{x}_{6}$ derived in the previous section, the carbon activity $a_{C}$ of the mixture can be calculated with Eq. 3-5. If the calculated carbon activity is lower than 1 , the gas mixture is in equilibrium and the solution $\mathrm{x}_{1} \rightarrow \mathrm{x}_{6}$ obtained in the previous section is the equilibrium solution.

The calculated carbon activity ac may be higher than one. Then the equilibrium of the mixture is not yet reached because carbon plateout takes place. Due to this, the carbon content $\bar{C}$ of the mixture decreases until the resulting carbon activity is equal to 1 . This can be calculated using a procedure similar to the one described in the last section.

In this procedure, the $\mathrm{K}_{\mathrm{P}_{1}}+\mathrm{K}_{\mathrm{P}_{3}}$ are kept constant at the given values and, instead of the $K_{P}$ 's, the $\bar{C}$ value is decreased in small increments. For first guess $x_{1}^{\prime} \rightarrow x_{6}^{\prime}$, the solution $x_{1} \rightarrow x_{6}$ resulting from the calculation in Section 5.1 is used. Then the new solution is calculated for the decreased value of $\vec{c}$. With this solution, the new $a_{C}$ value is then calculated. This procedure is repeated in a trial/error method until the calculated a $\mathrm{C}$ value is equal to 1 . The resulting solution $x_{1} \rightarrow x_{6}$ is considered the equilibrium state of the gas mixture and the integral decrease of $\bar{C}(\Delta \bar{C})$ is the amount of carbon plateout. 
6. THE COMPUTER PROGRAM BASED UPON THE MODEL

A computer program has been written which does the calculation of the model described in the previous sections. This program consists of four routines: the MAIN routine and the subroutines CONCEN, LINEQ, and DETERM. The principal routine of the program is the subroutine CONCEN and is therefore described first.

\subsection{THE SUBROUTINE CONCEN}

CONCEN does the iterative solution of the linearized system of Eqs. 4-1 through 4-5, as described in Section 4. It starts at a guess $x_{1}^{\prime}+x_{6}^{\prime}$ and calculates the solution $x_{1}+x_{6}$ for a given set of values $\mathrm{K}_{\mathrm{P}_{1}} \rightarrow \mathrm{K}_{\mathrm{P}_{3}}, \overline{0}, \overline{\mathrm{H}}$, and $\bar{c}$. The initial guess $x_{1}^{\prime}+x_{6}^{\prime}$ is created automatically in the MAIN routine.

At the beginning of each iteration, the coefficients $\alpha_{4 j}, \alpha_{5 j}, j=1,5$, $\mathrm{B}_{1}, \mathrm{~B}_{4}$, and $\mathrm{B}_{5}$ given in Eqs. 4-6 and 4-7 are calculated using the initial guess $x_{1}+x_{6}$. The coefficients $\alpha_{i j}, i=1,3, j=1,5$ are constant and taken over from the MAIN routine. The coefficients $B_{2}$ and $B_{3}$ are constant and taken over from MAIN as well. Then the linear system of Eqs. 4-1 through 4-5 is solved for the unknowns $x_{1} \rightarrow x_{5}$ by the subroutine LINEQ, which is described later. $x_{6}$ is then calculated using Eq. 3-4. This first solution $x_{1}+x_{6}$ is then used as guess $x_{1}^{\prime}+x_{6}^{\prime}$ for the next iteration; the calculation described above is repeated until the solution converges. The precision of the calculation and the convergence is tested in two separate tests:

1. A test is made to show if the solution of the linear system of equations done by the routine LINEQ is precise. This procedure using determinants implies the possibility that the precision of the computer, which for this calculation is set at $10^{-14}$, might 
not be high enough to give a correct solution in particular cases. For this purpose, a set of values $B_{1}^{\prime} \rightarrow B_{5}^{\prime}$ is calculated after each iteration using the solution $\mathrm{x}_{1}+\mathrm{x}_{5}$ and inserting it into Eqs. 4-1 through 4-5. Each value $B_{i}^{\prime}$ is then compared with its original corresponding value $B_{i}$. If the discrepancy of one of the calculated values is higher than $0.01 \%$ with respect to its original value, this is indicated by a printout: "Attention Solution of Linear Equations not Exact." The original and the calculated $\mathrm{B}_{1} \rightarrow \mathrm{B}_{5}$ and the concentration distribution $\mathrm{x}_{1} \rightarrow \mathrm{x}_{6}$ where this happened are printed out as well.

2. Another test is made to verify if the solution $x_{1} \rightarrow x_{5}$ satifies the solubility products (Eqs. 3-9 and 3-10). Therefore, after each iteration, the solubility products $F_{1}$ and $F_{2}$ are calculated by inserting $x_{1} \rightarrow x_{5}$ into Eqs. 3-9 and 3-10 and compared with the values of $\mathrm{K}_{\mathrm{P}_{1}}$ and $\mathrm{KP}_{2}$ for the respective calculation step (see Section 5.1). This test determines whether convergence has been reached, i.e., whether the iterations are finished. If the deviations between $F_{1}$ and $K_{P_{1}}$ and between $F_{2}$ and $K_{P_{2}}$ are both smaller than $0.01 \%$, the iterations are stopped and the solution is considered exact within the limits possible. Both tests ensure that after each calculation step (i.e., after the iterations are finished), the resulting $x_{1}+x_{6}$ satisfy Eqs. 3-2, 3-3, and 3-6 through 3-8. Equation $3-4$ is nevertheless satisfied.

\subsection{THE SUBROUTINES LINEQ AND DETERM}

The subroutine LINEQ solves the system of linear Eqs. 4-1 through 4-5 for the unknowns $x_{1} \rightarrow x_{5}$. This routine takes over the matrix $\left[\alpha_{i j}\right]$ and the vector $\left(B_{i}\right) i=1,5, j=1,5$ which are both calculated in CONCEN. First it calculates the determinant $D$ of the matrix $\left[\alpha_{i j}\right]$. Then in the matrix $\left[\alpha_{i j}\right]$, the columns $\left(\alpha_{i j}, j=k\right)$ are replaced successively by the vector $\left(B_{i}\right)$ for $k=1,5$ giving five different matrices for each of which the determinant $D_{k}$ is calculated with the subroutine DETERM. The unknowns $x_{1}+x_{5}$ are then obtained by setting $x_{k}=d_{k} / D$ for $k=1,5$. 
The subroutine DETERM transforms the matrix into its diagonal form, i.e., a transformation such that all coefficients below the diagonal become equal to zero. The product of the diagonal terms of the resulting matrix yields the determinant.

\subsection{THE MAIN ROUTINE}

The MAIN routine does the following:

1. Handles the input.

2. Constructs the initial fictitious solution necessary to start the iterative solution of the problem (see Section 5.1).

3. Creates the stepwise calculation by varying the $K_{P}$ values between those calculated for the fictitious solution and those given for the desired solution in small increments (see Section 5.1).

4. Calculates the carbon activity $a_{C}$. If $a_{C}>1$, it decreases the $\bar{C}$ content of the gas mixture stepwise in small increments in order to determine the equilibrium gas concentration distribution for $a_{C}=1$ in a trial/error procedure (see Section 5.2).

5. Provides the printout of intermediate and final results.

\subsubsection{The Input of the Program}

The input is organized in the following way. Each input card must have eight numbers. There is no format specified. A blank has to be between two different numbers. The maximum number of cards required for the calculation of one case is four. The first number on each card must be one of the integers $0,1,2$, or 3 . These integers specify how the computer is to interpret the remaining numbers on each card. 
One input card (usually the first) has to have the initial integer 1. The following number is the temperature for which the gas concentration distribution has to be calculated, e.g., $800^{\circ} \mathrm{C}$. Next, four numbers follow, which are the values for the solubility products $K_{P_{1}}+K_{P_{4}}$ at the tempera-

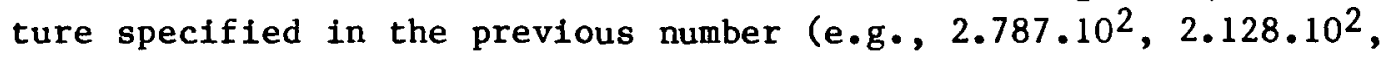
$1.181 .10^{9}$, and $\left.2.130 .10^{1}\right)$. Since each card must contain eight numbers altogether and the last numbers are not specified here, zeros have to be given as the last numbers.

Another input card has to have the integer 2 in the first place. This integer is followed by the molar concentrations of the constituents of the sample: $\mathrm{H}_{2}, \mathrm{CO}, \mathrm{CH}_{4}, \mathrm{H}_{2} \mathrm{O}, \mathrm{CO}_{2}, \mathrm{O}_{2}$, and the inert carrier gas (which may be helium or any mixture of inert gases). If there is no inert gas in the mixture, the last concentration value has to be set at zero.

An input card with the integer 3 in the first place may be used. The next number on this card specifies the number of steps in the intermediate calculations between a printout. The next number may be zero or one. Zero gives a normal printout of the results; one causes the program to print out all the matrices $\alpha_{1 j}$ and the vector $B_{i} i t$ produces during each calculation, which might be needed in case a result cannot be interpreted and in order to make it easier to detect and explain errors or discrepancies in the program in case they should occur. The next input number on this card gives the precision for the intermediate calculations (i.e., the relative agreement between the calculated values of $F_{1}, K_{P_{1}}$ and $F_{2}, K_{P_{2}}$ after each iteration) that must have been reached in order to finish the iteration. Generally this card is not inputted. Then the computer automatically sets the number of intermediate calculations per printout to equal 1. The printout is performed in the regular manner, and the precision is equal to $0.01 \%$.

The last input card of each case to be calculated must have eight zeros. This card advises the computer that no more input is to be expected and the calculation is to be started. 
There is one particular option in the input to run a continuation case (i.e., the concentration distribution will then be calculated for more than one temperature). Let us assume the concentration distribution has been calculated for $800^{\circ} \mathrm{C}$. The distribution is then to be calculated for $1000^{\circ} \mathrm{C}$ as well. In this case, only a card with the first index number 2 is inputted, containing $1000^{\circ} \mathrm{C}$ and the four $\mathrm{K}_{\mathrm{P}}$ values at $1000^{\circ} \mathrm{C}$. In order to start the calculation, a card with zeros must also be inputted. In that case, the program starts with the concentration distribution calculated in the previous case (i.e., $800^{\circ} \mathrm{C}$ ) and calculates the new distribution for $1000^{\circ} \mathrm{C}$. There is no limit to the number of continuation cases.

\subsubsection{Construction of the Fictitious Solution Necessary to Start the Iterative Solution Procedure and Rearrangement of the Initial Concentrations if the Initial $\mathrm{O}_{2}$ Concentration is Greater Than 0}

The input values of interest here are $x_{1}^{0}+x_{6}^{0}$. Several special cases have to be considered.

1. The normal case where all $\mathrm{x}_{1}^{\circ}+\underset{\times}{\times}$ are greater than zero and $\mathbf{x}_{6}^{0}=0$. The program calculates the overall oxygen, hydrogen, and carbon concentrations $\overline{0}, \overline{\mathrm{H}}$, and $\overline{\mathrm{C}}$ of the mixture using Eqs. 2-5 through 2-7. Then the fictitious values for $\mathrm{K}_{\mathrm{P}_{1}}$ nd $\mathrm{K}_{\mathrm{P}_{2}}$, i.e., $\mathrm{K}_{\mathrm{P}_{1}}^{0}$, and $\mathrm{K}_{\mathrm{P}_{2}}$, are constructed by putting $\mathrm{x}_{1}^{0} \rightarrow \mathrm{x}_{5}^{\circ}$ into $\mathrm{Eqs}, 3-2$ and 3-3.

2. One or more values of the initial concentrations $x_{1}^{0} \rightarrow x_{5}^{0}$ are equal to zero and $\mathrm{x}_{6}^{\circ}=0$. In this case, the constructed $\mathrm{K}_{\mathrm{P}_{1}}^{\circ}$ and $\mathrm{K}_{\mathrm{P}_{2}}^{\circ}$ could be either 0 or ${ }^{\infty}$, a case which cannot be treated. Therefore, a finite value has to be attributed by the user to the respective concentrations out of $x_{1}^{0}+x_{5}^{0}$ small enough not to change the resulting $\overline{0}, \overline{\mathrm{H}}$, and $\overline{\mathrm{C}}$ such that $\mathrm{K}_{\mathrm{P}_{1}}^{\circ}$ and $\mathrm{K}_{\mathrm{P}_{2}}$ become finite. 
3. The initial oxygen concentration $x_{6}^{\circ}$ is greater than zero. In this case, the initial $x_{1}^{0} \rightarrow x_{6}^{0}$ have to be rearranged because the model needs a value $x_{6}^{0}=x_{6}^{\prime}=0$ to start the iterations, since $x_{6}$ is regarded as a small correction term in the iterative calculation in Section 3. In this case, the program constructs a new value for $\dot{x}_{4}^{\circ} \equiv \mathrm{n}_{\mathrm{H}_{2}}^{\circ} \mathrm{O}$ by setting the new $\mathrm{x}_{4}^{\circ}$ equal to the given value $\mathrm{x}_{4}^{\circ}$ plus $2 x_{6}^{\circ}$ and setting the new $x_{6}^{0}=0$. Thus the correct overall oxygen content is calculated in Eq. 2-5. The increased value for $\mathrm{x}_{4}^{\circ}$ would lead to an $\overline{\mathrm{H}}$ value being too high in Eq. 2-6. Therefore, a new $\mathrm{x}_{1}^{\circ} \equiv \mathrm{n}_{\mathrm{H}_{0}}^{\circ}$ has to be constructed as we11, being equal to the given value $x_{1}^{0}$ minus 2 times the original value $x_{6}^{\circ}$. Thus $\bar{H}$ is not changed by the manipulation in $\mathrm{Eq} \cdot 2-5$. Then the $\mathrm{K}_{\mathrm{P}_{1}}$ and $\mathrm{K}_{\mathrm{P}_{2}}^{\circ}$ are constructed using the new $\mathrm{x}_{1}^{0}$ and $\mathrm{x}_{4}^{0}$ as described above. There is one restriction to the initial $x_{6}^{\circ}$ : it must be smaller than $x_{1}^{0} / 2$; otherwise the constructed new $x_{1}^{\circ}$ will become negative and would therefore not be a physical solution to the problem necessary to start the iterative solution.

\subsubsection{The Variation of $\mathrm{K}_{\mathrm{P}_{1}}+\mathrm{K}_{\mathrm{P}_{3}}$ by Increments}

First, the high fictitious value $10^{3}$ is attributed to $\mathrm{K}_{\mathrm{P}_{3}}^{\circ}$. Then the three $\mathrm{K}_{\mathrm{P}}$ 's have to be varied in small increments according to Section 5.1 . The program determines the number of increments by calculating the ratios $\stackrel{\circ}{\mathrm{K}_{\mathrm{P}_{1}}} / \mathrm{K}_{\mathrm{P}_{1}}=\mathrm{P}_{1}$ and $\stackrel{\circ}{\mathrm{K}_{\mathrm{P}_{2}}} / \mathrm{K}_{\mathrm{P}_{2}}=\mathrm{P}_{2}$ first. $\stackrel{\circ}{\mathrm{K}_{\mathrm{P}_{3}} / \mathrm{K}_{\mathrm{P}_{3}}}$ plays no significant role in this context, because $\mathrm{K}_{\mathrm{P}_{3}}$ determines the $\mathrm{O}_{2}$ content, which is always very sma11. The program takes the maximum value of $P_{1}, P_{2}$, and sets it equal to $P_{\max }$. Then the number of increments $n$ is determined according to $n=5.6 \mathrm{x}$ $\ln \left(\mathrm{P}_{\max }\right)$. The $K_{P}$ values are then varied in an exponential function between the initial and final values, the number of increments being $n$. After each increment, the subroutine CONCEN calculates a new concentration distribution. This has proven to be an optimal procedure as it gave solutions $\mathrm{x}_{1}+\mathrm{x}_{6}$ after each increment, being $0.01 \%$ exact after three iterations. In case the number of iterations needed to obtain the solution with CONCEN is higher than three, the increment is halved for subsequent calculations. As 
soon as the KP's have reached their final values, the concentration distribution calculated by CONCEN is regarded as a preliminary result. Then the carbon activity $a_{C}$ is calculated. $x_{1} \rightarrow x_{6}$ and $a_{C}$ are printed out. If the carbon activity is smaller than one, the calculated $x_{1} \rightarrow x_{6}$ are considered the equilibrium gas distribution and the calculation is finished.

The calculated value for the carbon activity may be higher than one. This means that carbon plateout takes place and the gas mixture has not yet reached the equilibrium state. In this case, the program continues the calculation by decreasing the $\bar{C}$ content of the mixture until the resulting $a_{C}$ reaches the value one.

\subsubsection{Equilibrium Calculation When Carbon Plateout Takes Place}

When carbon plateout takes place, the overall carbon content of the mixture $\bar{C}$ can no longer be considered constant. The program decreases $\bar{C}$ in small increments keeping the $\mathrm{K}_{\mathrm{P}_{1}}, \mathrm{~K}_{\mathrm{P}_{2}}$, and $\mathrm{K}_{\mathrm{P}_{3}}$ values constant. $\overline{\mathrm{C}}$ is decreased in each step by a certain factor $F$ (explained below). The subroutine CONCEN calculates the new $x_{1}+x_{6}$ distribution, ac is then calculated and the program repeats this procedure in a similar way as described in Section 7.3 until the calculated value ac is equal to one. The appropriate factor $F$ (i.e., the decrease of $\bar{C}$ in each step yielding a new solution $x_{1} \rightarrow x_{6}$ ) with no more than three iterations in the subroutine CONCEN is determined experimentally; the factor has the form $F(n)=\sum_{k=1}^{n} 0.5^{k}$. The first increment is calculated with $F(1)=0.5$. Then CONCEN is called, if it needs more than three iterations. The same calculation is repeated with $F(2)=0.75$, etc., until the number of iterations needed is not more than three. The factor used in this calculation may be applied then for the further decrease of $\bar{C}$ from its inftial value in a trial/error method until $a_{C}=1$. This state of the gas is considered the equilibrium state. The integral decrease in $\bar{C}(\Delta \bar{C})$ is calculated and printed out together with the concentration distribution of equilibrium $\mathrm{x}_{1} \rightarrow \mathrm{x}_{6}$. 


\section{CALCULATIONS PERFORMED WITH THE NEW MODEL}

The validity of the model has been verified by recalculation of cases that had been previously calculated with other models and published in the literature (Ref. 2). In this publication, two different programs were used to calculate the equilibrium. One program was used to calculate the equilibrium if no carbon plateout takes place. If it was found that carbon plateout took place, another program had to be used for the calculation of the resulting equilibrium. Both programs need an appropriate initial guess for the concentration distribution to be inputted to start the iterative solution.

7.1. CALCULATION OF THE EQUILIBRIUM OF TWO TEST GASES

Calculations were performed for five material corrosion test environments (gases), each of which was calculated for two different temperatures $\left(800^{\circ}\right.$ and $1000^{\circ} \mathrm{C}$ ). In all 10 cases the new model gave results which were in reasonable agreement with those quoted in the publication. Two typical calculations are quoted here. In the first case the gas concentration distribution is such that no carbon plateout takes place; in the second case carbon plateout does take place.

The first case is the DRAGON experimental gas and the second the JAERI-A gas. Table 1 gives the gas concentration distributions at room temperature. The total gas pressure is $1 \mathrm{~atm}$.

The authors who published their calculations quoted values for the constants $\mathrm{K}_{\mathrm{P}_{1}} \rightarrow \mathrm{K}_{\mathrm{P}_{4}}$ that are slightly different from those that they actually used in their calculations as can be directly shown from their results. The recalculation was done with those values $\mathrm{K}_{\mathrm{P}_{1}} \rightarrow \mathrm{K}_{\mathrm{P}_{4}}$ which were derived from their results. 
TABLE 1

TWO IMPURE HELIUM GASES FOR MATERIAL TESTS

\begin{tabular}{ccccccc}
\hline \multirow{2}{*}{$\begin{array}{c}\text { Experimental } \\
\text { Gas }\end{array}$} & $\mathrm{H}_{2}$ & $\mathrm{H}_{2} \mathrm{O}$ & $\mathrm{CO}$ & $\mathrm{CO}_{2}$ & $\mathrm{CH}_{4}$ & $\mathrm{O}_{2}$ \\
\cline { 2 - 4 } & 30 & 5 & 30 & 2 & 4 & 0 \\
DRAERI-A & 20 & 2 & 10 & 1 & 5 & 0 \\
\hline
\end{tabular}


The calculated equilibrium gas concentrations, the carbon plateout $\Delta C$, and the carbon activity are given in Table 2.

The values calculated for the DRAGON gas at $800^{\circ} \mathrm{C}$ and $1000^{\circ} \mathrm{C}$, where carbon plateout did not take place, are in perfect agreement with those quoted in the referenced paper. In the case of the JAERI-A gas where carbon plateout takes place, there was a slight disagreement between the concentrations calculated here with the new method and those quoted in the referenced paper. It is assumed that the disagreement results from the different calculation procedure employed in the referenced calculation in the case of carbon plateout. In that case, reactions different from those leading to the equilibrium Eqs. 2-1 through 2-3 were implied with a different set of $\mathrm{K}_{\mathrm{p}}$ 's. A small inconsistency between the $\mathrm{K}_{\mathrm{P}}$ 's used in the referenced calculations and the $\mathrm{K}_{\mathrm{P}_{1}} \rightarrow \mathrm{K}_{\mathrm{P}_{4}}$ used here may account for this discrepancy.

\subsection{CALCULATION OF THE INFLUENCE OF THE INITIAL OXYGEN AND WATER CONTENT ON THE CARBON AND OXYGEN POTENTIALS OF THE JAERI-A TEST GAS AT $800^{\circ}$ AND $1000^{\circ} \mathrm{C}$}

In the first calculation, the initial oxygen content of the JAERI-A gas was varied beween 0 and $7 \mu \mathrm{atm}$ and the resulting equilibrium distributions at $800^{\circ}$ and $1000^{\circ} \mathrm{C}$ were calculated. There were two fundamentally different ranges as far as the intial $0_{2}$ content is concerned, as shown in Fig. 1 . For $0_{2}$ values between 0 and $\sim 1 \mu$ atm, carbon plateout takes place and the carbon activity at equilibrium remained 1 ; the oxygen potentials were $\approx 10^{-30}$ and $10^{-28}$ for $800^{\circ}$ and $1000^{\circ} \mathrm{C}$, respectively. As soon as the initial oxygen content exceeds the value $\sim 1 \mu \mathrm{atm}$, there is no more carbon plateout, an almost vertical decrease of the carbon activity over 4 to 5 decades occurs, and an increase of the oxygen potentials over $\sim 10$ decades takes place. With further increasing initial oxygen content, both potentials level off.

Next the inftial $\mathrm{H}_{2} \mathrm{O}$ content was varied between 0 and $10 \mu \mathrm{atm}$. The resulting carbon and oxygen potentials at equilibrium are plotted in Fig. 2 . The water variation has a very similar effect on both potentials as did the oxygen variation. There is carbon plateout in the gas mixture until the 
TABLE 2

CALCULATED EOUILIBRIUM GAS CONCENTRATIONS

\begin{tabular}{|c|c|c|c|c|c|c|c|c|}
\hline & $\begin{array}{c}\mathrm{H}_{2} \\
(\mu \mathrm{atm})\end{array}$ & $\begin{array}{c}\mathrm{H}_{2} \mathrm{O} \\
(\mu \text { atm })\end{array}$ & $\begin{array}{c}\mathrm{CO} \\
(\mu \mathrm{atm})\end{array}$ & $\begin{array}{c}\mathrm{CO}_{2} \\
(\mu \mathrm{atm})\end{array}$ & $\begin{array}{c}\mathrm{CH}_{4} \\
(\mu \mathrm{atm})\end{array}$ & $\begin{array}{c}\mathrm{O}_{2} \\
\text { (uatm) }\end{array}$ & $\begin{array}{l}\Delta \mathrm{C} \\
(\mu \mathrm{atm})\end{array}$ & ${ }^{a} \mathrm{C}$ \\
\hline \multicolumn{9}{|l|}{ DRAGON } \\
\hline $800^{\circ} \mathrm{C}$ & 41.6 & 1.44 & 34.4 & 1.56 & $6.17 \times 10^{-9}$ & $8.59 \times 10^{-16}$ & -- & $7.60 \times 10^{-5}$ \\
\hline $1000^{\circ} \mathrm{C}$ & 41.1 & 1.87 & 34.9 & 1.13 & $1.59 \times 10^{-10}$ & $9.53 \times 10^{-12}$ & - & $9.78 \times 10^{-6}$ \\
\hline \multicolumn{9}{|l|}{ JAERI-A } \\
\hline $800^{\circ} \mathrm{C}$ & 32.0 & $3.42 \times 10^{-5}$ & 14.0 & $1.96 \times 10^{-5}$ & $4.81 \times 10^{-5}$ & $8.21 \times 10^{-25}$ & 2 & 1 \\
\hline $1000^{\circ} \mathrm{C}$ & 32.0 & $5.70 \times 10^{-6}$ & 14.0 & $1.79 \times 10^{-6}$ & $9.85 \times 10^{-6}$ & $1.47 \times 10^{-22}$ & 2 & 1 \\
\hline
\end{tabular}




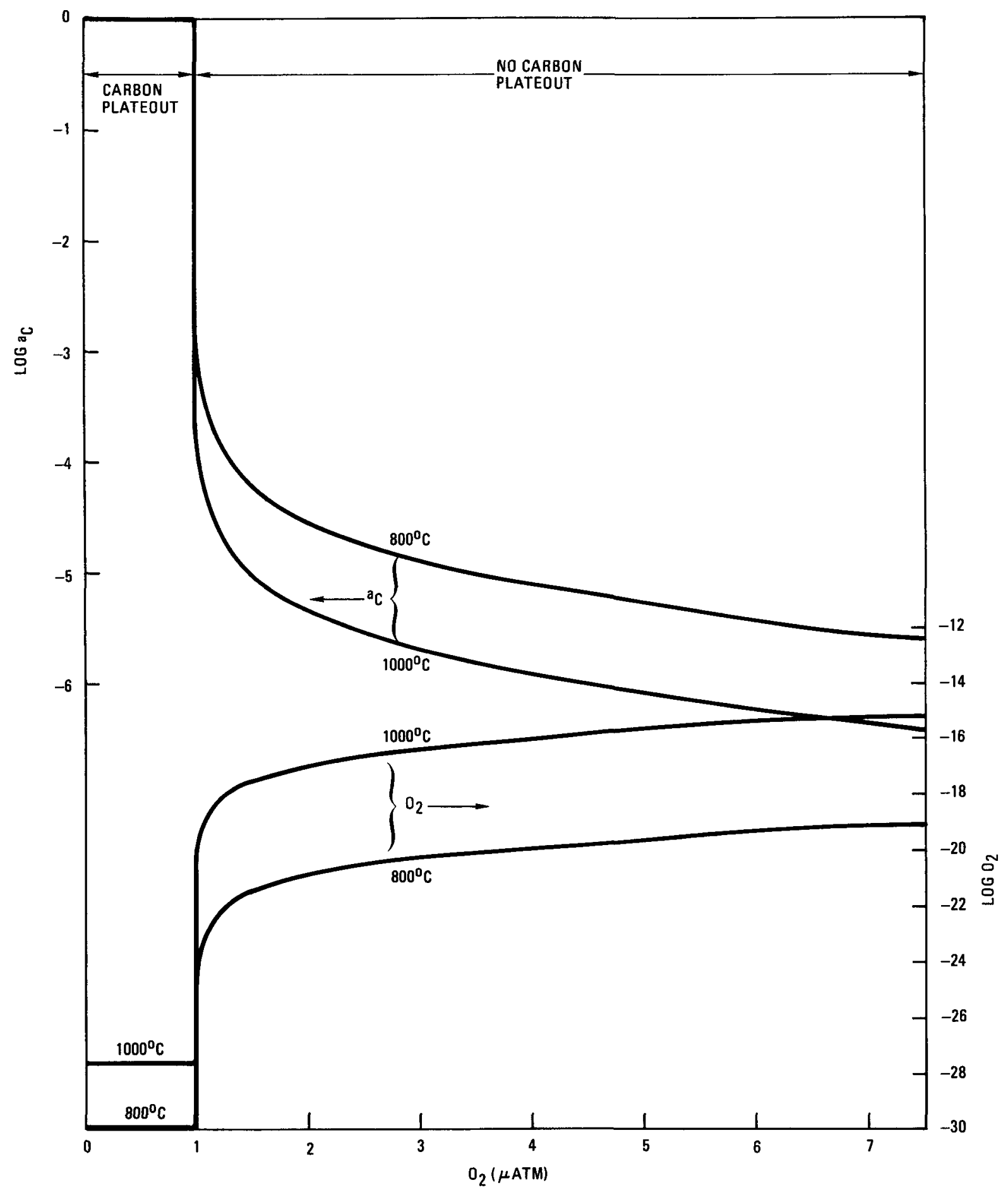

A-17146

Fig. 1. Effect of oxygen addition on the carbon activity and oxygen potential in the JAERI-A gas at $800^{\circ}$ and $1000^{\circ} \mathrm{C}$ 


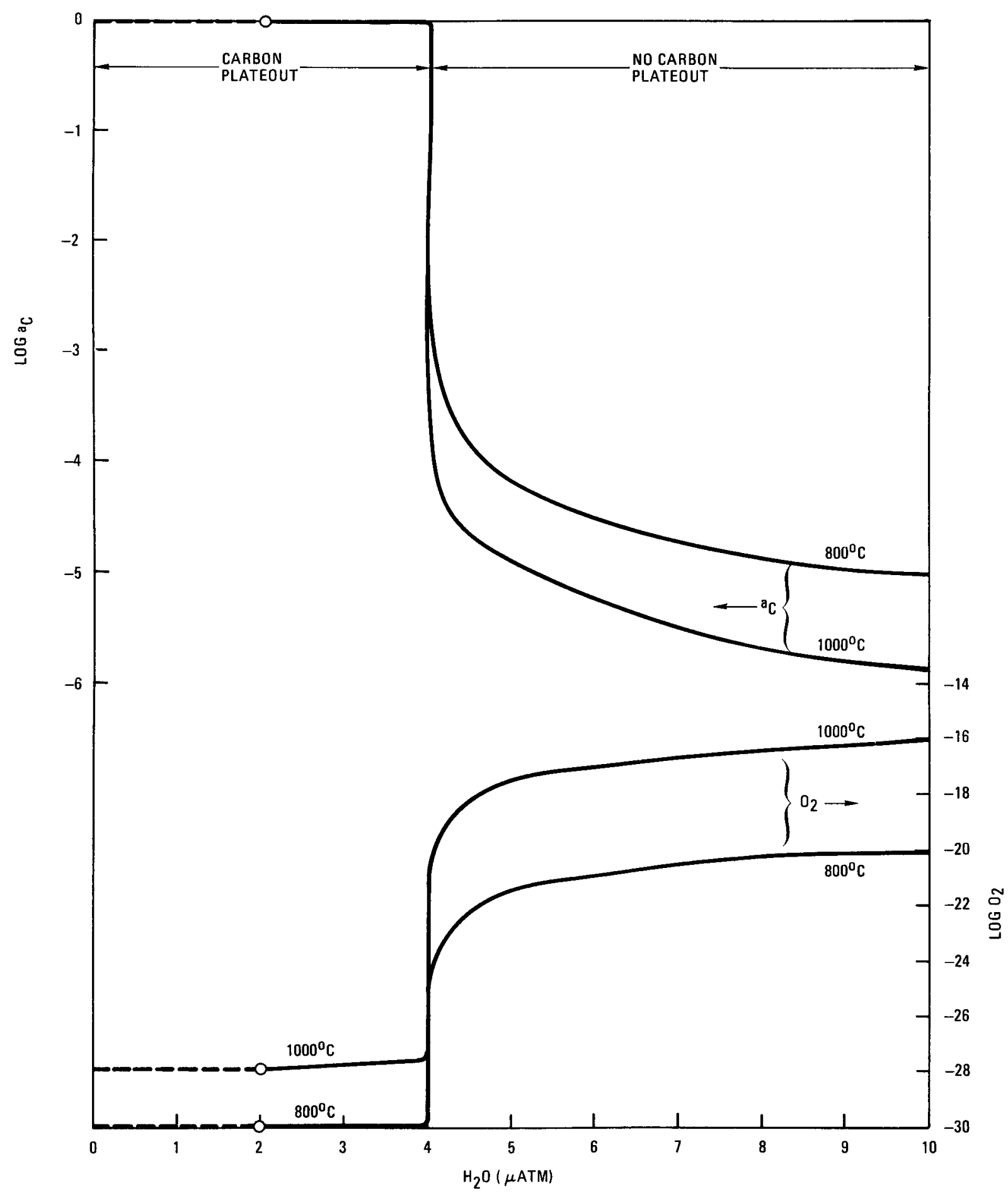

A. 17146

Fig. 2. Effect of water variation on the carbon activity and oxygen potential in the JAERI-A gas at $800^{\circ}$ and $1000^{\circ} \mathrm{C}$ 
infial water content reaches $\sim 4 \mu \mathrm{atm}$. Above that value, carbon is no longer plated out and the carbon and oxygen potentials both change very rapidly at first and then level off as before with increasing water content. Both figures show behavior identical to that described in Ref. 2 . 


\section{REFERENCES}

1. Darken, L. S., and R. W. Gurry, Physical Chemistry of Metals, McGrawH111 Book Company, Inc., 1953, pp. 200-228.

2. Nodor, T., et al., "Chemical Equilibrium of Impurity Gas Reactions in High-Temperature Helium for Material Tests," Boshku Gijutsu, 28, 3-9, 1979 . 


\section{ACKNOWLEDGMENTS}

The author would like to thank Dr. W. R. Johnson for valuable discussions and review; Dr. H. E. St. John for his assistance in the mathematlcal treatment of the problem; Dr. C. A. Rouse for reviewing the paper; B. Morel11 and J. Jayne for technical editing; and Susan Wynant and Nancy Brown for typing. 